\title{
Entransy analysis and optimization of irreversible Carnot-like heat engine
}

\author{
Mohammad H. Ahmadi ${ }^{1, a}$, Mohammad-Ali Ahmadi ${ }^{2}$ and Fathollah Pourfayaz ${ }^{1}$ \\ 1 Department of Renewable Energies, Faculty of New Sciences and Technologies, University of Tehran, Tehran, Iran \\ 2 Department of Petroleum Engineering, Ahwaz Faculty of Petroleum Engineering, Petroleum University of Technology \\ (PUT), Ahwaz, Iran
}

Received 14 October 2015, Accepted 14 March 2016

\begin{abstract}
Owing to the energy demands of the world and the issues involved with global warming, analyzing and optimizing power cycles have increased in importance. In this work, the concepts of entransy dissipation, power output, entropy generation, energy, exergy output, exergy efficiencies for irreversible heat engine cycles are applied as a means of analyzing them. This paper presents thermo-dynamical study of an irreversible heat engine cycle with the aim of optimizing the performance of the heat engine cycle. Moreover, four different strategies in the process of multi-objective optimization are proposed, and the outcomes of each strategy are evaluated separately. In the first scenario, in order to maximize the exergy output, ecological coefficient of performance (ECOP) and exergy-based ecological function (EECF), a multi-objective optimization algorithm was executed. In the second scenario, three objective functions comprising the ecological function, ECOP and exergetic performance criterion were maximized at the same time by employing multi objective optimization algorithms. In the third scenario, in order to minimize the entransy dissipation and maximize the ECOP and EECF, a multi-objective optimization algorithm was executed. In the fourth scenario, three objective functions comprising the exergetic performance criterion and ECOP and EECF were maximized at the same time by employing multi objective optimization algorithms. All the strategies in the present work are executed via the multi objective evolutionary algorithms based on NSGA $\|$ method. Finally, to govern the final answer in each strategy, three well-known decision makers are executed.
\end{abstract}

Key words: Entransy analysis / entransy dissipation / entropy generation / ecological function / optimization

\section{Introduction}

The thermal energy flow resulting from a temperature difference named heat transfer process, is one of the most common physical phenomena in the world, specifically in energy systems. Estimations all the global energy consumption propose that over $80 \%$ of the energy systems involve heat transfer processes. Therefore, enhanced heat transfer efficiency proposes an enormous potential for both reducing $\mathrm{CO}_{2}$ emission and conserving energy, thereby reducing global warming [1]. Because of these benefits, the optimization of heat transfer processes has increased in importance, which led to the development of a concept known as entransy. Entransy can be described

\footnotetext{
a Corresponding author:

mohammadhosein. ahmadi@gmail . com
}

as the heat transfer potential of a system. Thermodynamically, heat transfer is a non-equilibrium and irreversible process, and there is always entransy dissipation during a heat transfer process. Heat transfer dissipation is similar to entropy generation because they are a measurement of irreversible processes and both of them always increase. Entransy has been derived by using an analogy of electrical capacitance and can be defined as [2] (see Tab. 1).

$$
\dot{G}=\frac{1}{2} \dot{Q} T
$$

where $\dot{G}$ stands for the quantity of entransy (kWK), $\dot{Q}$ represents the heat stored in the object $(\mathrm{kW})$ and $T$ denotes the temperature of the object $(\mathrm{K})$. Using an analogy with electric capacitance, $\dot{Q}$ represents the thermal charge, which is similar to the electric charge, and $T$ represents the thermal potential, which is similar to the 
M.H. Ahmadi: Mechanics \& Industry 18, 204 (2017)

Table 1. Optimum answers achieved via decision makers for the first scenario.

\begin{tabular}{ccccccc}
\hline \multirow{2}{*}{$\begin{array}{c}\text { Decision Making } \\
\text { Method }\end{array}$} & \multicolumn{3}{c}{ Decision variables } & \multicolumn{3}{c}{ Objectives } \\
\cline { 2 - 7 } & $x$ & $y$ & $\tau$ & $E_{x}(\mathrm{~kW})$ & EECF & ECOP \\
\hline TOPSIS & 0.649 & 1.046 & 3.000 & 821.962 & 445.495 & 1.204 \\
LINMAP & 0.629 & 1.044 & 3.000 & 801.621 & 459.036 & 1.363 \\
Fuzzy & 0.446 & 1.040 & 3.000 & 467.976 & 385.386 & 4.762 \\
\hline
\end{tabular}

electrical potential. An entransy balance equation can be written from the thermodynamic point of view as follows [3]:

$$
\dot{G}_{\mathrm{H}}-\dot{G}_{\mathrm{L}}-\dot{G}_{\mathrm{d}}-\dot{G}_{\mathrm{w}}-\dot{G}_{\mathrm{lk}}=0
$$

where $\dot{G}_{\mathrm{H}}$ is the entransy flow at the hot temperature heat source, $\dot{G}_{\mathrm{L}}$ is the entransy flow at the heat low temperature heat source, $\dot{G}_{\mathrm{d}}$ is the entransy dissipation, $\dot{G}_{\mathrm{w}}$ is the work entransy and $\dot{G}_{\mathrm{lk}}$ is the heat leak entransy. Although there are papers in the literature regarding entransy [1-33], very few studies exist on the entransy analysis of thermodynamic cycles [2-6]. In this paper, entransy analyses of irreversible Carnot-like heat engine and refrigeration cycles are conducted. In addition, the entransy dissipation value of the systems is defined and the relationships between the power output, exergy output, entropy generation and entransy dissipation values for a heat engine and the relationships between power input, exergy input, entropy generation and entransy dissipation for a refrigeration cycle are defined.

Multi objective optimization is a great asset for solving engineering issues [34-36]. Özyer and colleagues [34] evolved an intellectual model for prospect calculation by using of evolutionary algorithms. The multi-objective optimization is performed by various engineering issues such as vehicle routing problems with Time Windows [35]. Blecic and colleagues [36] illustrated a decision support system called Bay MODE on the basis of multi objective optimization and Bayesian analysis.

Unraveling a multi-objective issue for the best performance is a complex issue because it requests synchronized fulfillment of different and occasionally conflicting objective functions. For unraveling such problems, various approaches including evolutionary algorithms (EA) were introduced in 20th century to help some multi objective issues [37]. The target of a multi-objective problem is to find a category of answers; each answer satisfies the objective functions [38]. The outcome will be a series of answers named Pareto frontier that reveals possible answers in the objective area. Multi-objective optimization method was widely employed in energy systems engineering exponentially [39-67].

In this work, four optimization scenarios are defined for the irreversible heat engine. In the first scenario, in order to maximize the exergy output, ECOP and EECF, a multi-objective optimization algorithm was executed. In the second scenario, three objective functions comprising the ecological function, ecological coefficient of performance and exergetic performance criterion were maximized at the same time by employing multi objective optimization algorithms. In the third scenario, in order to minimize the entransy dissipation and maximize the ECOP and EECF, a multi-objective optimization algorithm was executed. In the fourth scenario, three objective functions comprising the exergetic performance criterion and ECOP and exergy-based ecological function were maximized at the same time by employing multi objective optimization algorithms. For determining the final answer from Pareto frontiers (answers) three efficient decision makers were implemented comprising LINMAP, TOPSIS and Fuzzy techniques.

\section{System description and thermodynamic analysis}

\subsection{System description and assumptions}

A heat engine is described as a machine that produces work by absorbing heat from a high temperature heat source and rejecting a proportion of this heat to low temperature heat sink. The most widely known heat engine is the Carnot engine developed by Sadi Carnot. This engine is assumed to be totally reversible, and it provides scientists or engineers the upper limits of the work that can be generated in a system and the maximum thermal efficiencies obtained from it. Similar to Carnot engines, Carnot refrigeration can be defined. A Carnot refrigeration system operates as a Carnot heat engine in reverse, i.e., work is obtained from environment to the machine to transfer heat from the low temperature heat source to high temperature heat sink. As with a Carnot heat engine, a Carnot refrigerator is assumed as totally reversible. Hence, a Carnot refrigerator uses the minimum amount of work and has the maximum COP (coefficient of performance). However, a reversible cycle does not exist in reality. The irreversible Carnot-like heat engine model studied in this paper are shown in Figure 1.

The below presumptions are included in the thermodynamic analysis:

- All processes are irreversible.

- The system operates in steady state conditions.

- The environmental conditions are $T_{\mathrm{o}}=298.15 \mathrm{~K}$ and $P_{\mathrm{o}}=100 \mathrm{kPa}$.

The thermodynamic calculations were performed according to the model used by Chen et al. [68]. Although similar analyses and methods exist in the literature [69-73], they do not include an entransy analysis. 


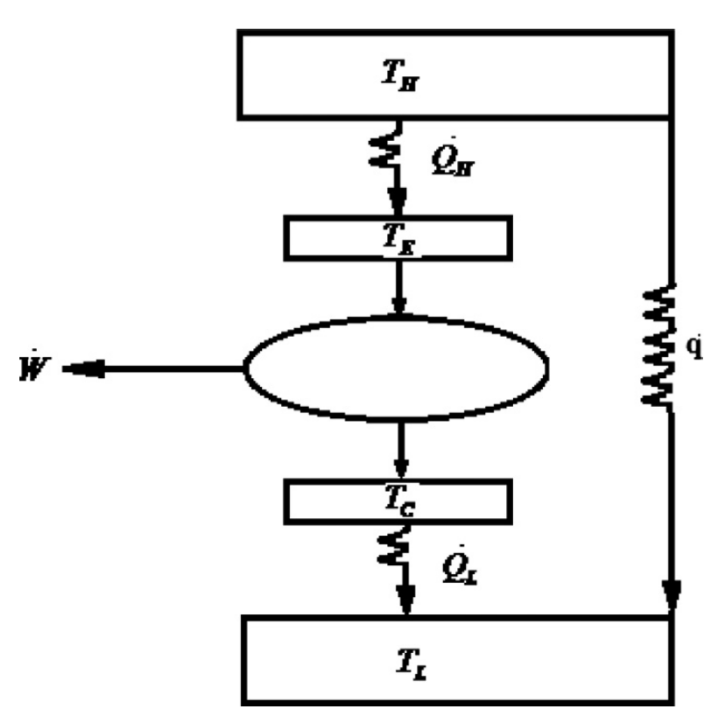

Fig. 1. Schematic of the irreversible heat engine.

\subsection{Thermodynamic analysis of the irreversible heat engine}

The heat absorbed by the system $\dot{Q}_{\mathrm{H}}$ from the high temperature heat source at the evaporator, the heat rejected by the system $\dot{Q}_{\mathrm{L}}$ to the low temperature heat sink at the condenser and the heat leakage $\dot{q}$ can be defined as follows:

$$
\begin{aligned}
\dot{Q}_{\mathrm{H}} & =k_{\mathrm{H}}\left(T_{\mathrm{H}}-T_{\mathrm{E}}\right) \\
\dot{Q}_{\mathrm{L}} & =k_{\mathrm{L}}\left(T_{\mathrm{E}}-T_{\mathrm{L}}\right) \\
\dot{q} & =c\left(T_{\mathrm{H}}-T_{\mathrm{L}}\right)
\end{aligned}
$$

where $k_{\mathrm{H}}$ and $k_{\mathrm{L}}$ are the heat conductances $\left(\mathrm{kW} . \mathrm{K}^{-1}\right)$ of the evaporator and the condenser, respectively, $c$ is the heat conductance of the heat leak $\left(\mathrm{kW} . \mathrm{K}^{-1}\right), T_{\mathrm{H}}, T_{\mathrm{L}}$, $T_{\mathrm{E}}$ and $T_{\mathrm{C}}$ are the temperature of the hot temperature heat source, the temperature of the low temperature heat source, the evaporator temperature and the condenser temperature $(\mathrm{K})$. Because heat transfer in the condenser and evaporator does not occur at a constant temperature, all the heat transfer processes are irreversible. Some parameters are provided to facilitate the calculations: the temperature ratio of the evaporator and condenser:

$$
x=\frac{T_{\mathrm{C}}}{T_{\mathrm{E}}}
$$

the ratio of the heat conductances

$$
y=\frac{k_{\mathrm{H}}}{k_{\mathrm{L}}}
$$

and the sum of the heat conductances

$$
z=k_{\mathrm{H}}+k_{\mathrm{L}}
$$

From the first law of thermodynamics, which formulates the energy balance for any system, the following equation can be written:

$$
\dot{W}=\dot{Q}_{\mathrm{H}}-\dot{Q}_{\mathrm{L}}
$$

In which $\dot{W}(\mathrm{~kW})$ stands for the power output of the system. From the second law of thermodynamics an internally irreversible parameter $(I)$ is defined as:

$$
I \frac{\dot{Q}_{\mathrm{H}}}{T_{\mathrm{E}}}=\frac{\dot{Q}_{\mathrm{L}}}{T_{\mathrm{C}}}
$$

$I$ is greater than one for irreversible cycles and it is equal to zero for endoreversible cycles. The entropy generation equation can be defined as:

$$
S_{\text {gen }}=\left(\frac{\dot{Q}_{\mathrm{L}}}{T_{\mathrm{L}}}-\frac{\dot{Q}_{\mathrm{H}}}{T_{\mathrm{H}}}\right)+\dot{q}\left(\frac{1}{T_{\mathrm{L}}}-\frac{1}{T_{\mathrm{H}}}\right)
$$

where $S_{\text {gen }}\left(\mathrm{kW} \cdot \mathrm{K}^{-1}\right)$ is the entropy generation. The exergy output of the system is:

$$
E x=\dot{Q}_{\mathrm{H}}\left(1-\frac{T_{0}}{T_{\mathrm{H}}}\right)-\dot{Q}_{\mathrm{L}}\left(1-\frac{T_{0}}{T_{\mathrm{L}}}\right)
$$

In which $E x$ denotes the exergy output, and $T_{0}$ represents the temperature of the surrounding environment. The energetic and exergetic efficiencies of the system can be defined by Equations (13) and (14), correspondingly:

$$
\begin{aligned}
\eta & =\frac{\dot{W}}{\dot{Q}_{\mathrm{H}}} \\
\varphi & =\frac{\dot{W}}{E x}
\end{aligned}
$$

The entransy equations of $\dot{G}_{\mathrm{d}} ; \dot{G}_{\mathrm{H}} ; \dot{G}_{\mathrm{L}} ; \dot{G}_{\mathrm{W}} ; \dot{G}_{\mathrm{lk}}$ can be defined as follows:

$$
\begin{aligned}
\dot{G}_{\mathrm{H}} & =\frac{1}{2} k_{\mathrm{E}}\left(T_{\mathrm{H}}^{2}-T_{\mathrm{E}}^{2}\right) \\
\dot{G}_{\mathrm{L}} & =\frac{1}{2} k_{\mathrm{C}}\left(T_{\mathrm{C}}^{2}-T_{L}^{2}\right) \\
\dot{G}_{\mathrm{W}} & =\dot{W} T_{0} \\
\dot{G}_{\mathrm{lk}} & =\frac{1}{2} \dot{q} T_{0} \\
\dot{G}_{\mathrm{d}} & =\dot{G}_{\mathrm{H}}-\dot{G}_{\mathrm{L}}-\dot{G}_{\mathrm{W}}-\dot{G}_{\mathrm{lk}}
\end{aligned}
$$

Using (3)-(19), the power output, exergy output, entropy generation, entransy dissipation, energy efficiency and exergy efficiency can be formulated as below:

$$
\begin{aligned}
\dot{W} & =\frac{z y(I x-1)\left(T_{\mathrm{L}}-T_{\mathrm{H}} x\right)}{x(1+y)(I+y)} \\
E x & =\frac{z y\left(T_{\mathrm{L}} T_{0}-T_{\mathrm{H}}\left(T_{\mathrm{L}}-I T_{\mathrm{L}} x+I T_{0} x\right)\right)\left(T_{\mathrm{L}}-T_{\mathrm{H}} x\right)}{x T_{\mathrm{H}} T_{\mathrm{L}}(1+y)(I+y)}
\end{aligned}
$$

see equation (22) next page.

$$
\begin{aligned}
\eta & =1-I x \\
\phi & =\frac{(1-I x) T_{\mathrm{H}}}{\left(T_{\mathrm{H}}-T_{\mathrm{L}}\right)}
\end{aligned}
$$




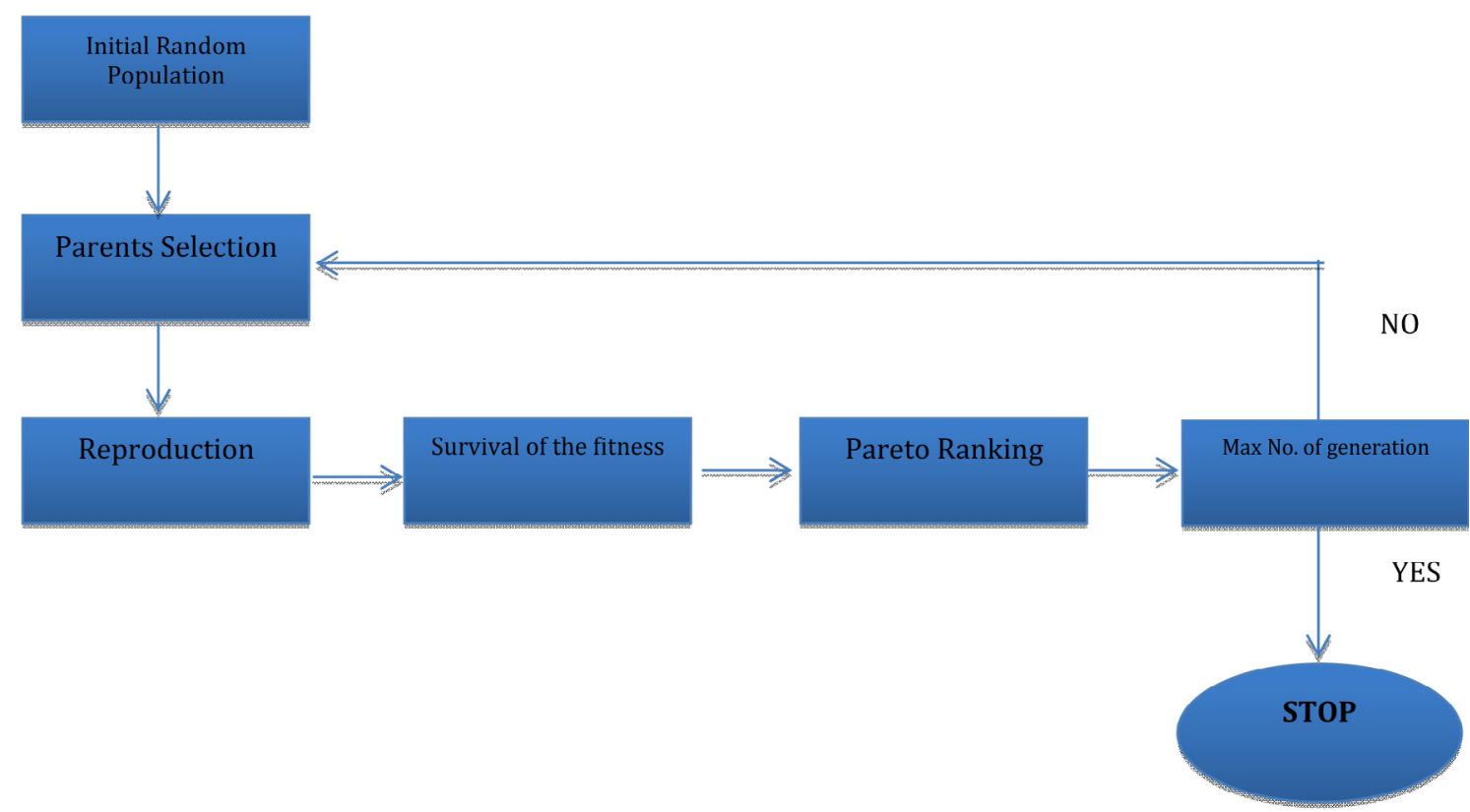

Fig. 2. Graphical demonstration of the MOEA approach employed in this research [39-67]

$$
S_{\text {gen }}=\frac{c\left(T_{\mathrm{H}}-T_{\mathrm{L}}\right)^{2} x(1+y)(I+y)+z y\left(T_{\mathrm{L}}-T_{\mathrm{H}} x\right)\left(T_{\mathrm{H}}-I T_{\mathrm{L}} x\right)}{x T_{\mathrm{H}} T_{\mathrm{L}}(1+y)(I+y)}
$$

Ecological function, ECOP and exergetic performance criterion are calculated as following:

$$
\begin{aligned}
E C F & =W-T_{0} S_{\text {gen }} \\
E C O P & =\frac{W}{T_{0} S_{\text {gen }}} \\
E P C & =\frac{E x}{T_{0} S_{\text {gen }}}
\end{aligned}
$$

Exergy-based ecological function (EECF) $(\mathrm{kW})$ of the cycle is written:

$$
E E C F=E x-T_{0} S_{\text {gen }}
$$

\section{Multi-objective optimization}

The multi-objective optimization method was executed to optimize heat engine system to specify the system design variables. To assess this, Genetic algorithms (GA) implement iterative and stochastic search process to determine optimum solution. The chief concepts of GA and box-chart of the aforementioned methodology are depicted through Figure 2 [39-67].

\subsection{Objective functions, decision variables and constraints}

The $E x$ and ECOP and EECF are three objective functions for the first scenario, which are evaluated via Equations (21), (26) and (28).
The ecological function, ECOP and exergetic performance criterion are three objective functions for the second scenario, which are evaluated via Equations (25)(27).

The entransy dissipation $\left(\dot{G}_{\mathrm{d}}\right)$ and ECOP and EECF are three objective functions for the third scenario, which are evaluated via Equations (19), (26) and (28).

The ECOP, exergetic performance criterion and exergy-based ecological function are three objective functions for the fourth scenario, which are evaluated via Equations (26)-(28).

The below decision parameters were opted in this research:

$x$ : The temperature ratio of the evaporator and condenser.

$y$ : The ratio of the heat conductances.

$\tau$ : The temperature ratio.

Even though the decision variables would be different in the optimization process, each should be in a proper interval. By assuming the below limits the objective functions are resolved:

$$
\begin{aligned}
0.2 & \leq x \leq 0.65 \\
1 & \leq y \leq 1.6 \\
2.5 & \leq \tau \leq 3
\end{aligned}
$$

To determine the final solution from Pareto optimum frontier, three efficient decision makers comprising TOPSIS, Fuzzy and LINMAP are employed. Detail explanations of the aforementioned decision makers can be found in references [45-67]. 


\section{Results and discussion}

The sensitivity of the objective functions to the decision variables was examined. As shown in Figure 3a, the ecological function (ECF) increases with the increasing of the temperature ratio of the evaporator and condenser $x$ until the ecological function (ECF) reaches maximum value and then reduces with the rising of the temperature ratio of the evaporator and condenser $x$.

As shown in Figure 3b, the exergy-based ecological function $(\mathrm{EECF})$ rises with the rising of the temperature ratio of the evaporator and condenser $x$ until the exergybased ecological function (EECF) reaches maximum value and then reduces with the rising of the temperature ratio of the evaporator and condenser $x$.

As shown in Figure 3c, the entransy dissipation $\left(\dot{G}_{\mathrm{d}}\right)$ rises with the rising of the temperature ratio of the evaporator and condenser $x$ until the entransy dissipation $\left(\dot{G}_{\mathrm{d}}\right)$ reaches maximum and then reduces with the rising of the temperature ratio of the evaporator and condenser $x$.

As shown in Figure 3d, the exergetic performance criterion (EPC) reduces with the increasing of the temperature ratio of the evaporator and condenser $x$ until the exergetic performance criterion (EPC) is minimized and then rises with the rising of the temperature ratio of the evaporator and condenser $x$ until the exergetic performance criterion (EPC) reaches maximum and then reduces with the rising of the temperature ratio of the evaporator and condenser $x$.

As shown in Figure 3e, the ECOP decreases with the increasing of the temperature ratio of the evaporator and condenser $x$ until the ECOP is minimized and then increases with the increasing of the temperature ratio of the evaporator and condenser $x$ until the ECOP reaches maximum and then reduces with the rising of the temperature ratio of the evaporator and condenser $x$.

The sensitivity of the objective functions to the decision variables was examined. As shown in Figure 4a, the ecological function (ECF) rises with the rising of the temperature ratio of the evaporator and condenser $x$ until the ecological function (ECF) reaches maximum and then reduces with the rising of the temperature ratio of the evaporator and condenser $x$. As illustrated in Figure 4a, consider constant value of the temperature ratio of the evaporator and condenser $x$, by increasing the value of the temperature ratio the value of the ecological function (ECF) increased.

As shown in Figure 4b, the EECF rises with the rising of the temperature ratio of the evaporator and condenser $x$ until the EECF reaches maximum value and then reduces with the rising of the temperature ratio of the evaporator and condenser $x$. As shown in Figure $4 \mathrm{~b}$, at constant value of the temperature ratio of the evaporator and condenser $x$, by rising the value of the temperature ratio the value of the exergy-based ecological function (EECF) increased.

As shown in Figure 4c, the entransy dissipation $\left(\dot{G}_{\mathrm{d}}\right)$ rises with the rising of the temperature ratio of the evaporator and condenser $x$ until the entransy dissipation $\left(\dot{G}_{\mathrm{d}}\right)$ reaches maximum value and then reduces with the rising of the temperature ratio of the evaporator and condenser $x$. As shown in Figure $4 \mathrm{c}$, at constant value of the temperature ratio of the evaporator and condenser $x$, by rising the value of the temperature ratio the value of the entransy dissipation $\left(\dot{G}_{\mathrm{d}}\right)$ increased.

As shown in Figure 4d, the exergetic performance criterion (EPC) reduces with the increasing of the temperature ratio of the evaporator and condenser $x$ until the exergetic performance criterion (EPC) is minimized and then increases with the rising of the temperature ratio of the evaporator and condenser $x$ until the exergetic performance criterion (EPC) reaches maximum value and then reduces with the rising of the temperature ratio of the evaporator and condenser $x$.

As shown in Figure 4e, the ECOP decreases with the increasing of the temperature ratio of the evaporator and condenser $x$ until the ECOP is minimized and then rises with the rising of the temperature ratio of the evaporator and condenser $x$ until the ECOP reaches maximum value and then reduces with the rising of the temperature ratio of the evaporator and condenser $x$.

\subsection{Results of first scenario}

Using multi-objective optimization on the basis of the NSGA-II method, the exergy output, the EECF and the ECOP are maximized in the same time. The objective functions and the restrictions which were employed in the optimization, are formulated by Equations (21), (26) and (28) and (29)-(31) respectively. The temperature ratio of the evaporator and condenser, the ratio of the heat conductances, are presumed as design variables in the optimization process. Following properties of the irreversible heat cycle system are presumed as below [74]:

$$
\begin{aligned}
& z=10\left(\mathrm{~kW} \cdot \mathrm{K}^{-1}\right), \quad T_{0}=298.15(\mathrm{~K}), \\
& c=0.02\left(\mathrm{~kW} \cdot \mathrm{K}^{-1}\right), \quad T_{L}=400(\mathrm{~K})
\end{aligned}
$$

Pareto optimal frontier for three objective functions, objective function associated to the exergy output, EECF and ECOP of the irreversible heat engine cycle are depicted in Figure 5.

Table 1 demonstrates the optimal outputs achieved for decision parameters and objective functions via running TOPSIS, Fuzzy and LINMAP decision makers for first scenario.

Table 2 demonstrates the error evaluation of the used decision makers. Two different statistical error indexes including MAAE (Maximum Absolute Percentage Error) and MAPE (Mean Absolute Percentage Error) are employed to calculate the errors of each decision maker. Table 2 presents the MAAE and MAPE of each decision maker.

\subsection{Results of second scenario}

Three considered objective functions for optimization are the ecological function, ECOP and exergetic 
M.H. Ahmadi: Mechanics \& Industry 18, 204 (2017)

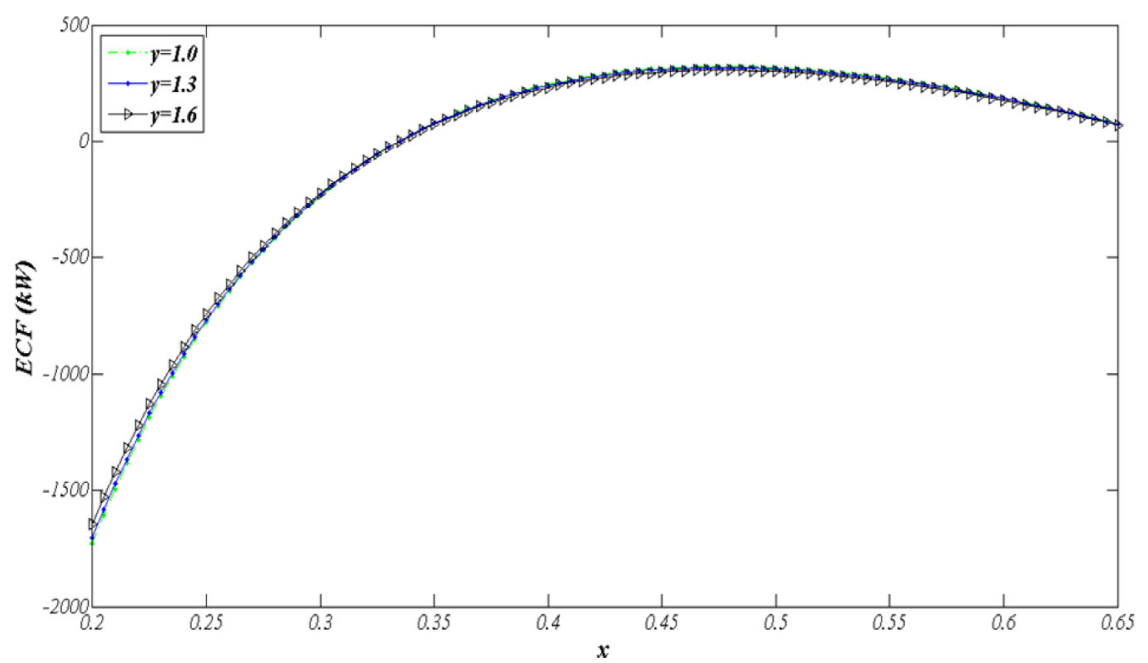

(a)

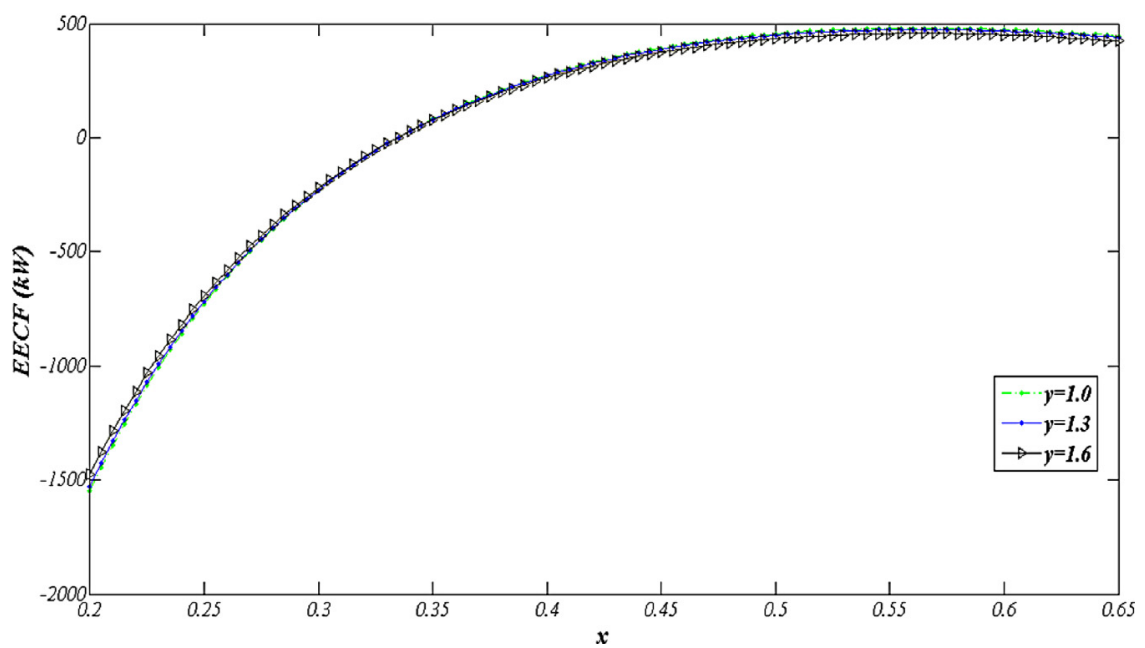

(b)

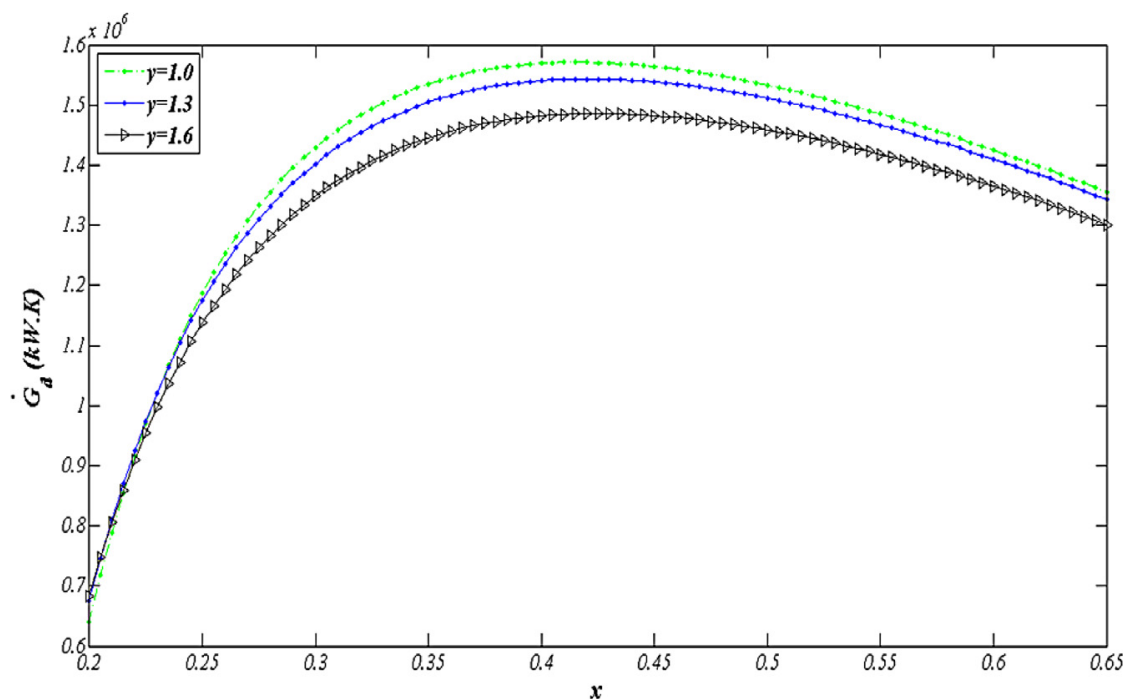

(c)

Fig. 3. Effects of the temperature ratio of the evaporator and condenser $x$ at various values of the ratio of the heat conductances (y) on the (a) the ecological function, (b) the exergy-based ecological function (c) the EECF, (d) the exergetic performance criterion, (e) the ECOP in $\tau=3$. 
M.H. Ahmadi: Mechanics \& Industry 18, 204 (2017)

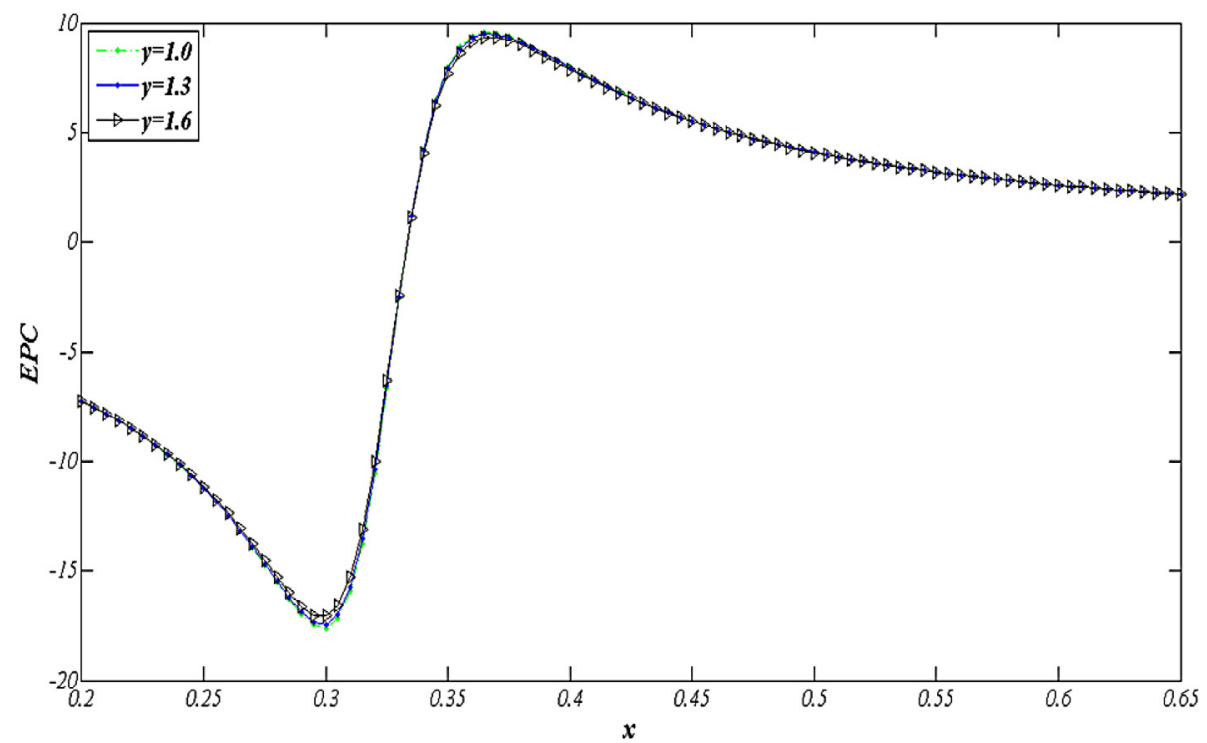

(d)

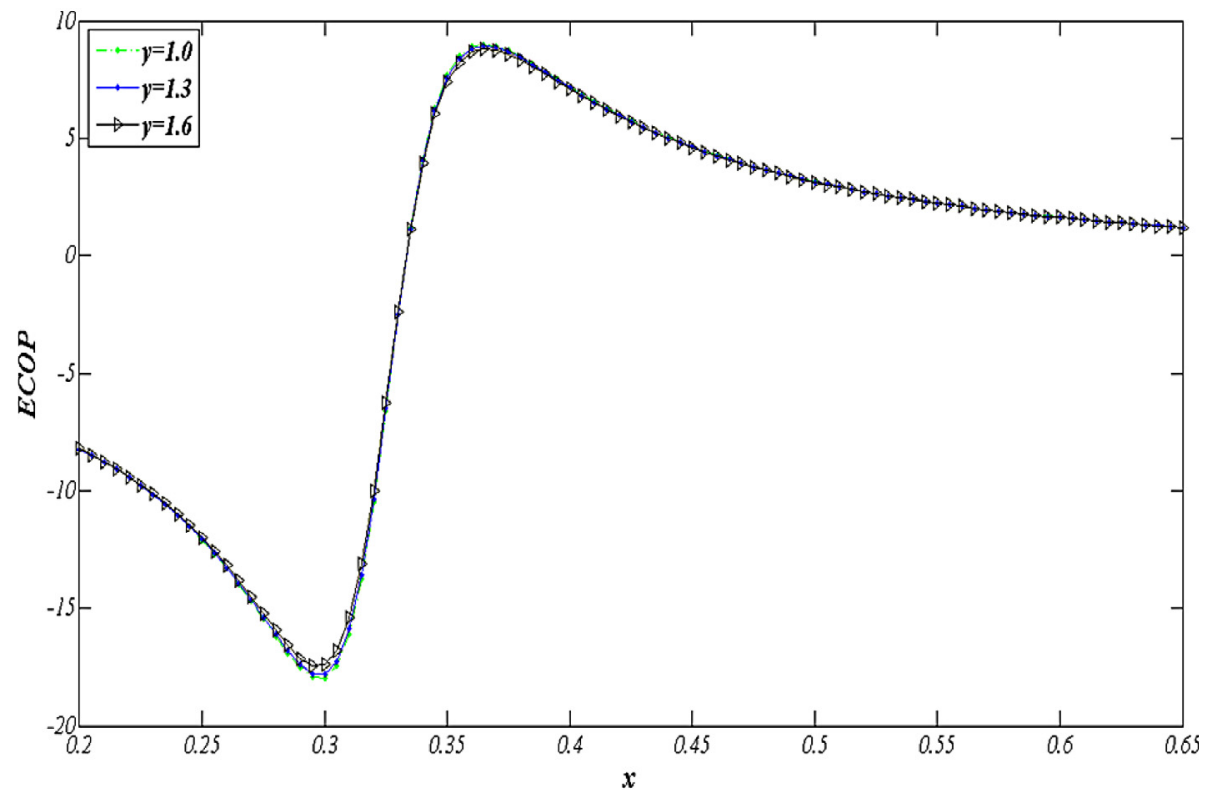

(e)

Fig. 3. Continued.

Table 2. Error analysis of the answers achieved for the first scenario.

\begin{tabular}{cccccccccc}
\hline $\begin{array}{c}\text { Decision Making } \\
\text { Method }\end{array}$ & \multicolumn{3}{c}{ TOPSIS } & \multicolumn{3}{c}{ LINMAP } & & Fuzzy \\
\hline Objectives & $E x$ & EECF & ECOP & $E x$ & EECF & ECOP & $E x$ & EECF & ECOP \\
Max Error \% & 0.226 & 0.149 & 0.810 & 0.150 & 0.030 & 0.334 & 0.118 & 0.070 & 0.277 \\
Average Error \% & 0.222 & 0.134 & 0.769 & 0.127 & 0.016 & 0.258 & 0.061 & 0.043 & 0.199 \\
\hline
\end{tabular}


M.H. Ahmadi: Mechanics \& Industry 18, 204 (2017)

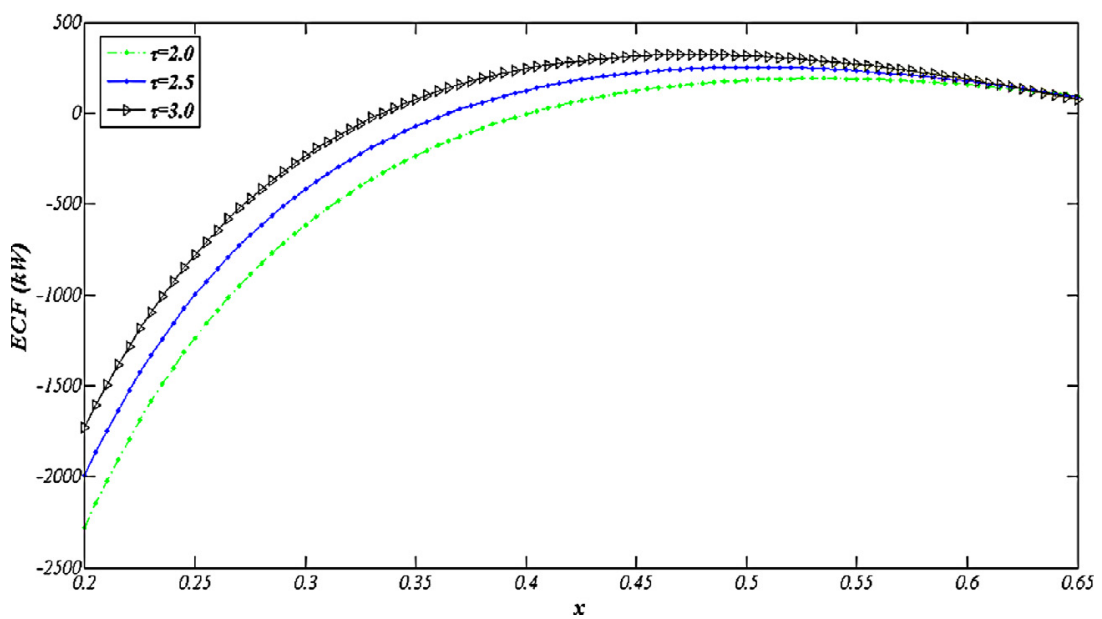

(a)

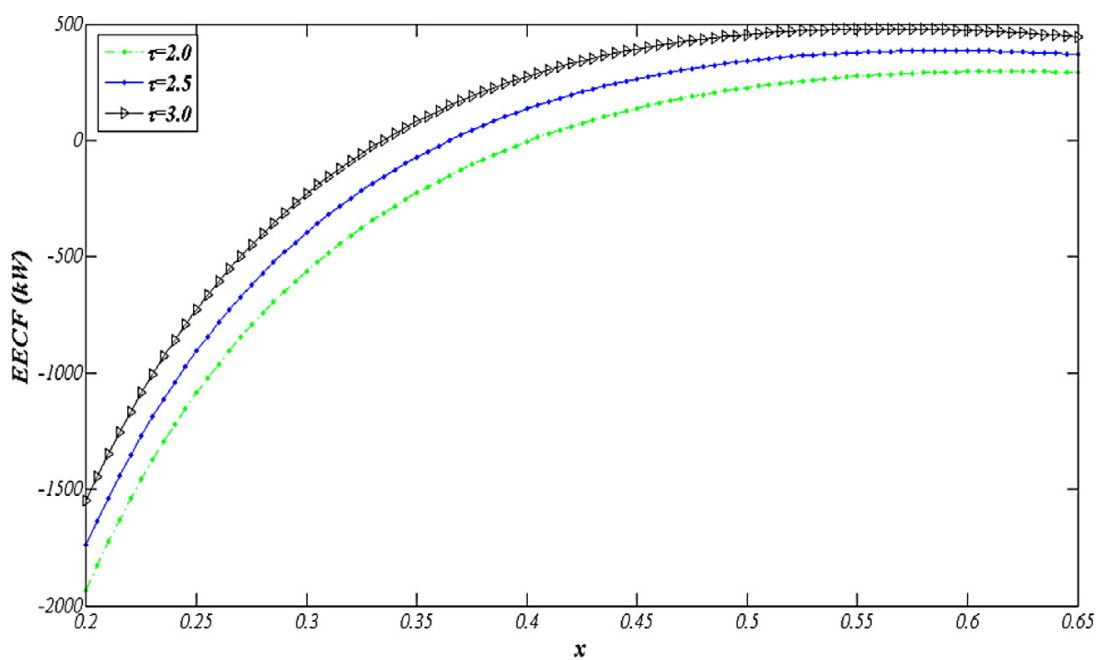

(b)

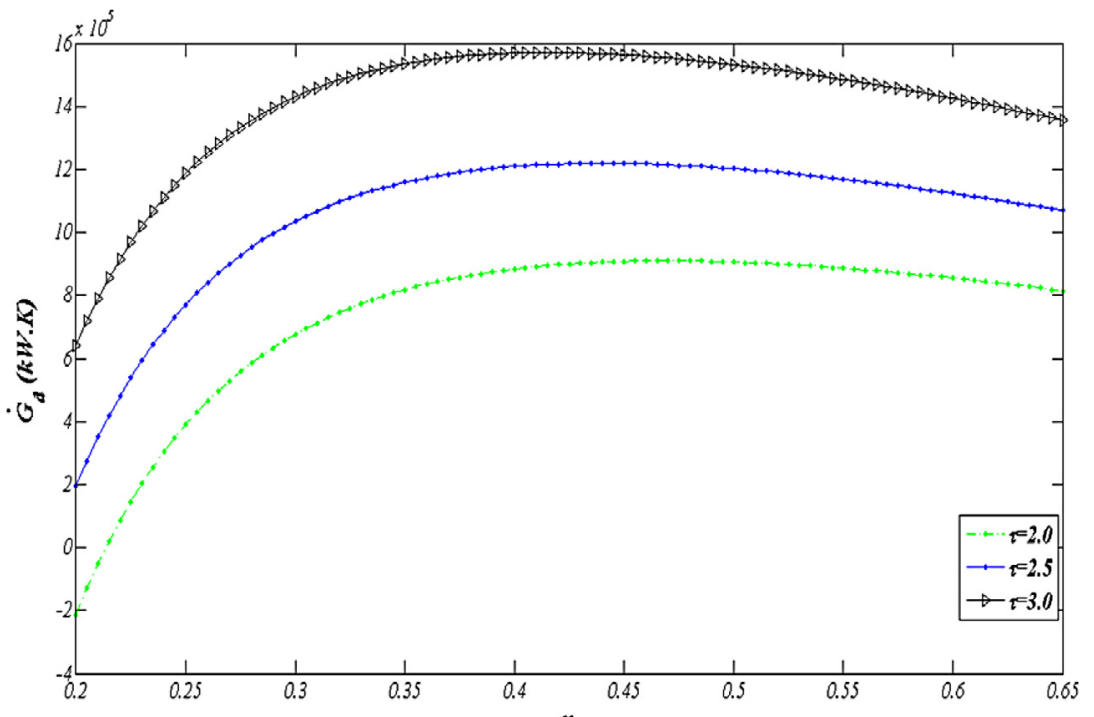

(c)

Fig. 4. Effects of the temperature ratio of the evaporator and condenser $x$ at various values of the ratio of the temperature ratio $\tau$ on the (a) the ecological function, (b) the exergy-based ecological function (c) the EECF, (d) the exergetic performance criterion, (e) the ECOP in $y=1$. 


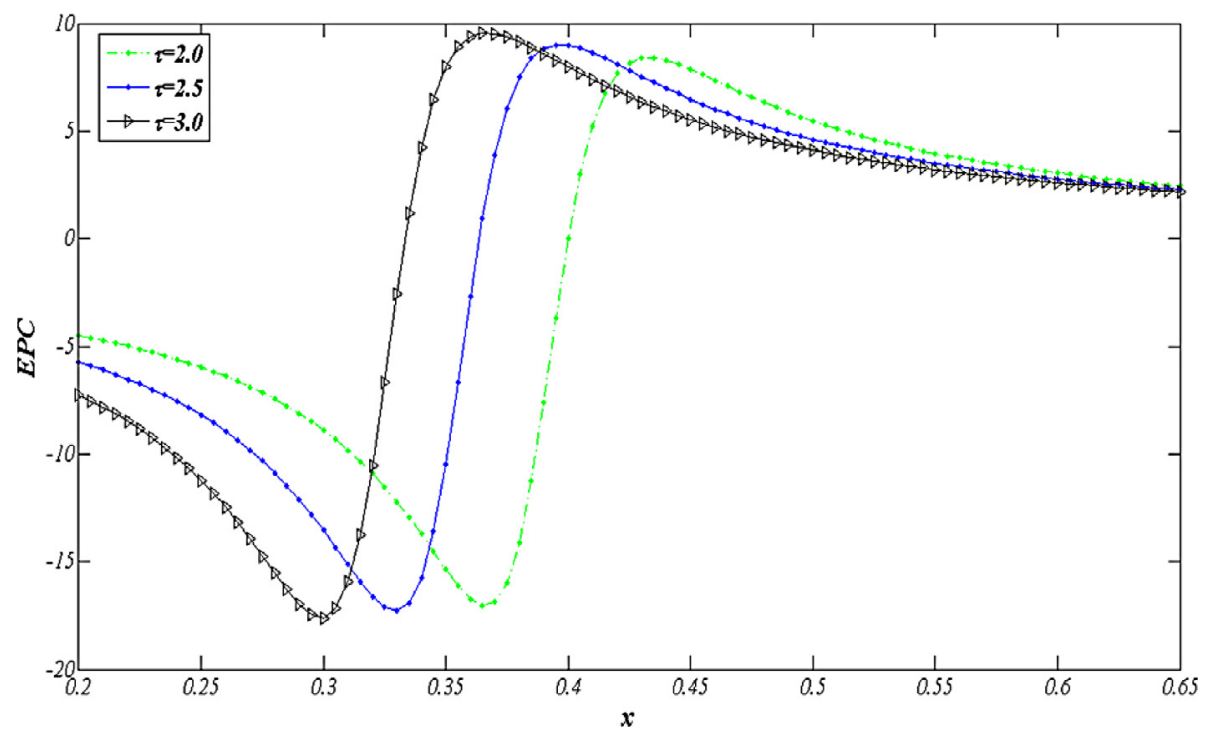

(d)

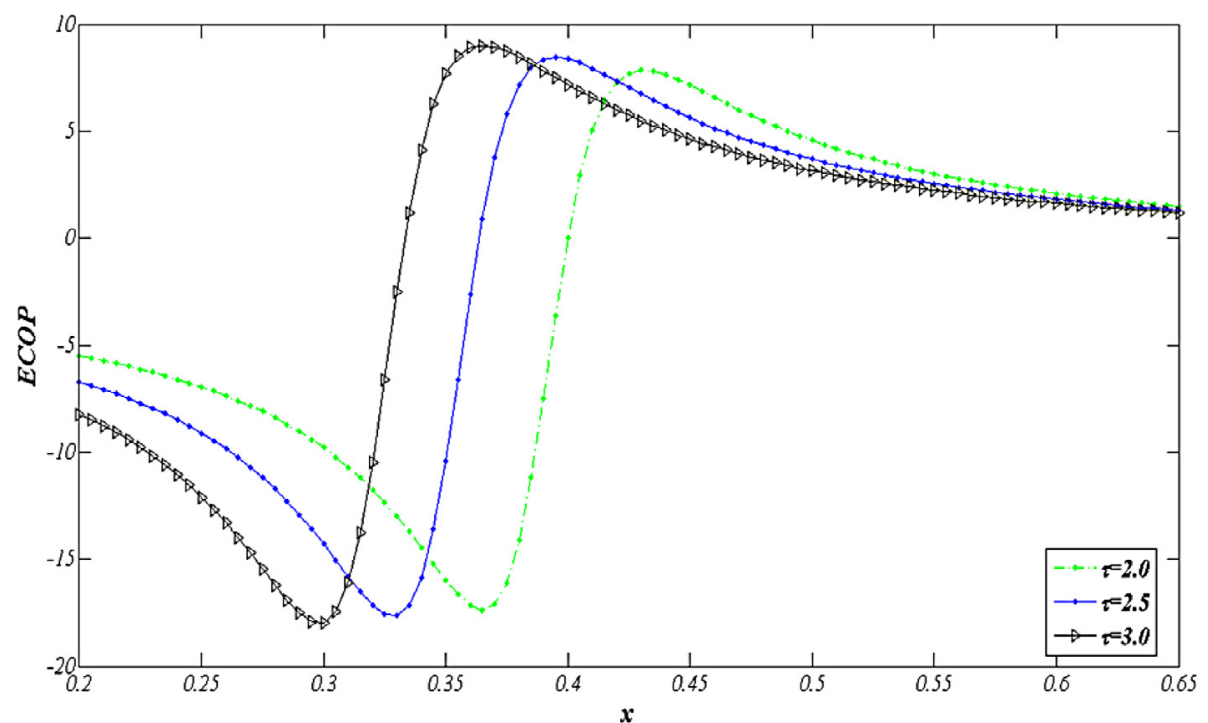

(e)

Fig. 4. Continued.

performance criterion (should be maximized) which formulated via Equations (25)-(27), correspondingly.

Objective functions are expressed by Equations (25)-(27) and restrictions are presented by Equations (29)-(31).

The properties of the irreversible heat engine cycle are assumed as below [74]

$$
\begin{aligned}
& z=10\left(\mathrm{~kW} \cdot \mathrm{K}^{-1}\right), \quad T_{0}=298.15(\mathrm{~K}), \\
& c=0.02\left(\mathrm{~kW} \cdot \mathrm{K}^{-1}\right), \quad T_{\mathrm{L}}=400(\mathrm{~K})
\end{aligned}
$$

Figure 6 shows the Pareto frontier in the suggested objectives' space achieved in the optimization strategy. Three final answers were chosen via the Fuzzy Bellman-Zadeh, LINMAP and TOPSIS decision-makers which are highlighted in Figure 6.
Table 3 demonstrates the optimal outputs achieved for decision parameters and objective functions via running TOPSIS, Fuzzy and LINMAP decision makers for second scenario.

Same as previous strategy, Table 4 demonstrates the error evaluation of the used decision makers. Two different statistical error indexes including MAAE and MAPE are employed to calculate the errors of each decision maker. Table 4 presents the MAAE and MAPE of each decision maker.

\subsection{Results of third scenario}

Using multi-objective optimization on the basis of the NSGA-II method, the entransy dissipation $\left(\dot{G}_{\mathrm{d}}\right)$ is 


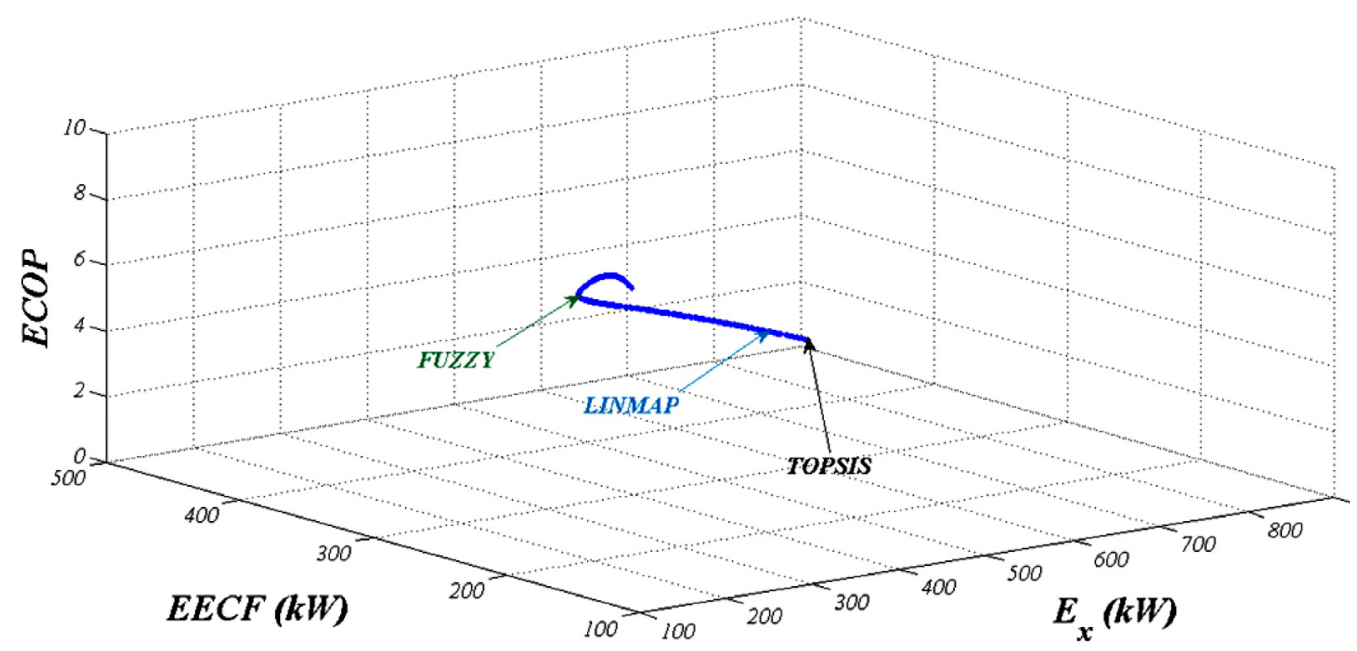

Fig. 5. Pareto optimum frontier in the objectives' space for first scenario.

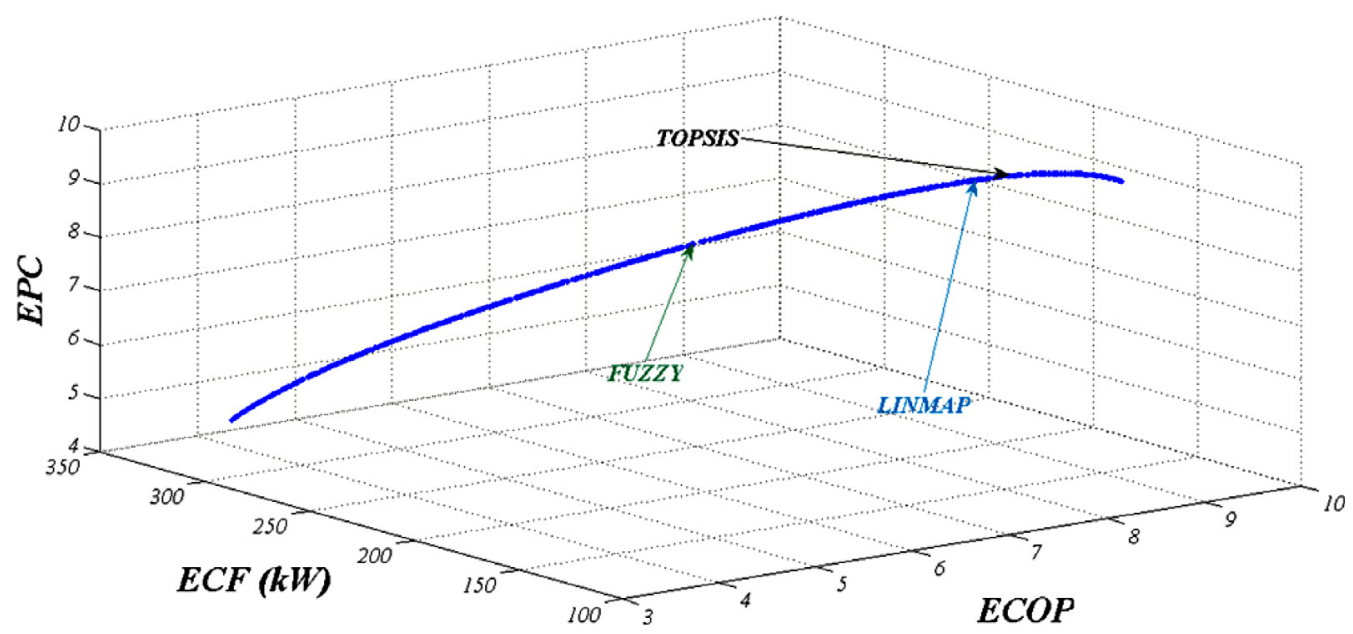

Fig. 6. Pareto optimum frontier in the objectives' space for second scenario.

Table 3. Optimum answers achieved via decision makers for second scenario.

\begin{tabular}{ccccccc}
\hline \multirow{2}{*}{$\begin{array}{c}\text { Decision Making } \\
\text { Method }\end{array}$} & \multicolumn{3}{c}{ Decision variables } & \multicolumn{3}{c}{ Objectives } \\
\cline { 2 - 7 } & $x$ & $y$ & $\tau$ & ECOP & ECF $(\mathrm{kW})$ & EPC \\
\hline TOPSIS & 0.376 & 1.028 & 3.000 & 8.670 & 178.240 & 9.328 \\
LINMAP & 0.379 & 1.029 & 3.000 & 8.517 & 187.310 & 9.198 \\
Fuzzy & 0.403 & 1.029 & 3.000 & 6.952 & 250.937 & 7.763 \\
\hline
\end{tabular}

Table 4. Error analysis of the answers achieved for the second scenario.

\begin{tabular}{cccccccccc}
\hline $\begin{array}{c}\text { Decision Making } \\
\text { Method }\end{array}$ & \multicolumn{3}{c}{ TOPSIS } & & \multicolumn{3}{c}{ LINMAP } & & \multicolumn{2}{c}{ Fuzzy } \\
\hline Objectives & ECOP & ECF (kW) & EPC & ECOP & ECF (kW) & EPC & ECOP & ECF (kW & EPC \\
Max Error \% & 0.108 & 0.344 & 0.083 & 0.074 & 0.200 & 0.059 & 0.029 & 0.040 & 0.025 \\
Average Error \% & 0.065 & 0.212 & 0.050 & 0.056 & 0.145 & 0.045 & 0.017 & 0.022 & 0.014 \\
\hline
\end{tabular}




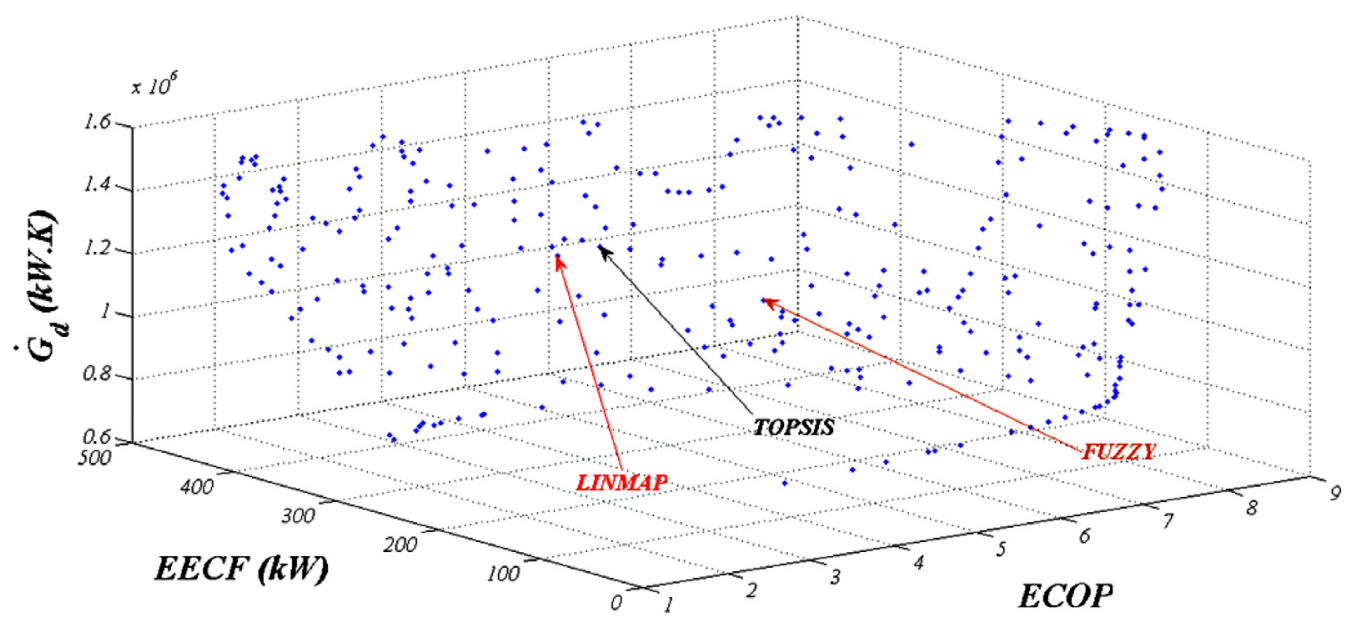

Fig. 7. Pareto optimum frontier in the objectives' space for third scenario.

Table 5. Optimum answers achieved via decision makers for third scenario.

\begin{tabular}{ccccccc}
\hline \multirow{2}{*}{$\begin{array}{c}\text { Decision Making } \\
\text { Method }\end{array}$} & \multicolumn{3}{c}{ Decision variables } & \multicolumn{2}{c}{ Objectives } \\
\cline { 2 - 7 } & $x$ & $y$ & $\tau$ & ECOP & EECF $(\mathrm{kW})$ & $G_{\mathrm{d}}(\mathrm{kW} . \mathrm{K})$ \\
\hline TOPSIS & 0.471 & 1.518 & 2.809 & 4.410 & 319.508 & 1237442.903 \\
LINMAP & 0.486 & 1.358 & 2.776 & 4.022 & 329.957 & 1215227.508 \\
Fuzzy & 0.459 & 1.503 & 2.690 & 5.429 & 243.329 & 1093384.648 \\
\hline
\end{tabular}

Table 6. Error analysis of answers achieved for the third scenario.

\begin{tabular}{cccccccccc}
\hline $\begin{array}{c}\text { Decision Making } \\
\text { Method }\end{array}$ & & TOPSIS & \multicolumn{3}{c}{ LINMAP } & \multicolumn{3}{c}{ Fuzzy } \\
\hline Objectives & ECOP & EECF & $\dot{G}_{\mathrm{d}}$ & ECOP & EECF & $\dot{G}_{\mathrm{d}}$ & ECOP & EECF & $\dot{G}_{\mathrm{d}}$ \\
\hline Max Error \% & 2.734 & 7.766 & 6.737 & 2.055 & 3.081 & 3.199 & 5.713 & 5.307 & 6.139 \\
Average Error \% & 1.639 & 7.404 & 6.433 & 1.334 & 2.603 & 3.026 & 3.526 & 4.869 & 3.238 \\
\hline
\end{tabular}

minimized and ECOP and EECF are maximized simultaneously. The objective functions and the restrictions are expressed via Equations (19), (26) and (28) and (29)(31) respectively. The temperature ratio of the evaporator and condenser, the ratio of the heat conductances are presumed as design variables in the optimization process. The below properties of the irreversible heat engine cycle system are presumed as follows [74]:

$$
\begin{aligned}
& z=10\left(\mathrm{~kW} \cdot \mathrm{K}^{-1}\right), T_{0}=298.15(\mathrm{~K}), \\
& c=0.02\left(\mathrm{~kW} \cdot \mathrm{K}^{-1}\right), T_{\mathrm{L}}=400(\mathrm{~K})
\end{aligned}
$$

Pareto optimum frontier for three objective functions, objective function associated to the entransy dissipation $\left(\dot{G}_{\mathrm{d}}\right)$, ECOP and EECF of the irreversible heat engine cycle are represented in Figure 7.

Table 5 demonstrates the optimal outputs achieved for decision parameters and objective functions via running TOPSIS, Fuzzy and LINMAP decision makers for the third scenario.

Same as previous strategy, Table 6 demonstrates the error evaluation of the used decision makers. Two different statistical error indexes including MAAE and MAPE are employed to calculate the errors of each decision maker. Table 6 presents the MAAE and MAPE of each decision maker.

\subsection{Results of fourth scenario}

Using multi-objective optimization based on the NSGA-II algorithm, the ECOP, exergetic performance criterion and EECF are maximized simultaneously. The objective functions and the restrictions are formulated by Equations (26)-(28) and (29)-(31) respectively. The temperature ratio of the evaporator and condenser, the ratio of the heat conductances are presumed as design variables in the optimization process. The below features of the irreversible heat engine cycle system are presumed as follows [74]:

$$
\begin{aligned}
& z=10\left(\mathrm{~kW} \cdot \mathrm{K}^{-1}\right), T_{0}=298.15(\mathrm{~K}), \\
& c=0.02\left(\mathrm{~kW} \cdot \mathrm{K}^{-1}\right), T_{\mathrm{L}}=400(\mathrm{~K})
\end{aligned}
$$

Pareto optimum frontier for three objective functions, objective function associated to the ECOP , exergetic performance criterion and EECF of the irreversible heat engine cycle are represented in Figure 8. 


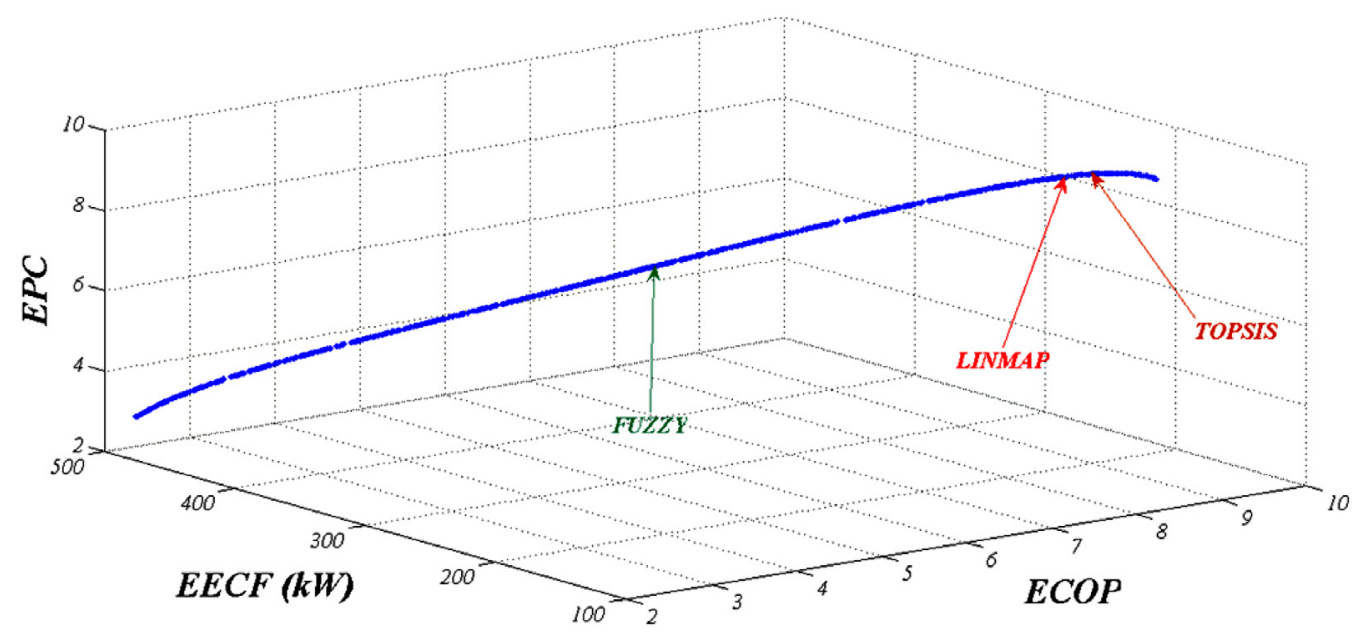

Fig. 8. Pareto optimum frontier in the objectives' space for fourth scenario.

Table 7. Optimum answers achieved via decision makers for the fourth scenario.

\begin{tabular}{ccccccc}
\hline \multirow{2}{*}{$\begin{array}{c}\text { Decision Making } \\
\text { Method }\end{array}$} & \multicolumn{3}{c}{ Decision variables } & \multicolumn{3}{c}{ Objectives } \\
\cline { 2 - 7 } & $x$ & $y$ & $\tau$ & ECOP & EECF $(\mathrm{kW})$ & EPC \\
\hline TOPSIS & 0.374 & 1.032 & 3.000 & 8.787 & 184.050 & 9.423 \\
LINMAP & 0.376 & 1.037 & 3.000 & 8.646 & 195.338 & 9.308 \\
Fuzzy & 0.421 & 1.033 & 3.000 & 5.912 & 332.937 & 6.774 \\
\hline
\end{tabular}

Table 8. Error analysis of the results achieved for the fourth scenario.

\begin{tabular}{cccccccccc}
\hline $\begin{array}{c}\text { Decision Making } \\
\text { Method }\end{array}$ & & TOPSIS & & \multicolumn{3}{c}{ LINMAP } & & \multicolumn{3}{c}{ Fuzzy } \\
\hline Objectives & ECOP & EECF $(\mathrm{kW})$ & EPC & ECOP & EECF $(\mathrm{kW})$ & EPC & ECOP & EECF (kW) & EPC \\
\hline Max Error \% & 0.178 & 0.833 & 0.128 & 0.211 & 0.658 & 0.164 & 0.164 & 0.141 & 0.137 \\
Average Error \% & 0.107 & 0.507 & 0.078 & 0.198 & 0.657 & 0.154 & 0.148 & 0.117 & 0.124 \\
\hline
\end{tabular}

Table 7 demonstrates the optimal outputs achieved for decision parameters and objective functions via running TOPSIS, Fuzzy and LINMAP decision makers for the fourth scenario.

Same as previous strategy, Table 8 demonstrates the error evaluation of the used decision makers. Two different statistical error indexes including MAAE and MAPE are employed to calculate the errors of each decision maker. Table 8 presents the MAAE and MAPE of each decision makers.

\section{Conclusions}

In this paper the thermodynamic analysis is applied on an irreversible heat engine cycle. Effects of the temperature ratio of the evaporator and condenser, the ratio of the heat conductances, the temperature ratio are included in the evaluation of the exergy output, the ecological function, the exergetic performance criterion, the exergy-based ecological function and the ECOP of an irreversible heat engine cycle using thermodynamic analysis. Moreover, optimum settings of the aforementioned objective functions comprising the exergy output, the ecological function, the exergetic performance criterion, the exergy-based ecological function and the ECOP are specified.

In the multi-objective optimization approach, three separate variables, the temperature ratio of the evaporator and condenser, the ratio of the heat conductances, the temperature ratio, are assumed as the decision parameters. Three effective decision makers were employed to indicate a final solution from the solutions achieved from multi-objective optimization.

\section{References}

[1] Q. Chen, X.G. Liang, Z.Y. Guo, Entransy theory for the optimization of heat transfer - a review and update, Int. J. Heat Mass Transfer 63 (2013) 65-81

[2] Z.Y. Guo, H.Y. Zhu, X.G. Liang, Entransy - a physical quantity describing heat transfer ability, Int. J. Heat Mass Transfer 50 (2007) 2545-2556

[3] X.T. Cheng, X.G. Liang, Entransy loss in thermodynamic processes and its application, Energy 44 (2012) 964-972

[4] M.T. Xu, The thermodynamic basis of entransy and entransy dissipation, Energy 36 (2011) 4272-4277 
[5] X.T. Cheng, W.H. Wang, X.G. Liang, Entransy analysis of open thermodynamic systems, Chin. Sci. Bull. 57 (2012) 2934-2940

[6] W. Wang, X.T. Cheng, X.G. Liang, Entropy and entransy analyses and optimizations of the Rankine cycle, Energy Convers. Manage. 68 (2013) 82-88

[7] W. Liu, Z.C. Liu, H. Jia, et al., Entransy expression of the second law of thermodynamics and its application to optimization in heat transfer process, Int. J. Heat Mass Transfer 54 (2011) 3049-3059

[8] L.G. Chen, S.H. Wei, F.R. Sun, Constructal entransy dissipation minimization for volume-point heat conduction, J. Phys. D 41 (2008) 195-506

[9] Z.H. Xie, L.G. Chen, F.R. Sun, Constructal optimization for geometry of cavity by taking entransy dissipation minimization as objective, Sci. China Ser. E: Tech. Sci. 52 (2009) 3413-3504

[10] Q. Chen, J.X. Ren, Generalized thermal resistance for convective heat transfer and its relation to entransy dissipation, Chin. Sci. Bull. 53 (2008) 3753-3761

[11] X.T. Cheng, X.G. Liang, Entransy flux of thermal radiation and its application to enclosures with opaque surfaces, Int. J. Heat Mass Transfer 54 (2011) 269-278

[12] X.T. Cheng, X.H. Xu, X.G. Liang, Radiative entransy flux in enclosures with nonisothermal or non-grey, opaque, diffuse surfaces and its application, Sci. China: Technol. Sci. 54 (2011) 2446-2456

[13] X.T. Cheng, X.G. Liang, Computation of effectiveness of two-stream heat exchanger networks based on concepts of entropy generation, entransy dissipation and entransydissipation-based thermal resistance, Energy Convers. Manage. 58 (2012) 163-170

[14] X.T. Cheng, X.H. Xu, X.G. Liang, Application of entransy to optimization design for parallel thermal network of thermal control system in spacecraft, Sci. China: Technol. Sci. 54 (2011) 964-971

[15] X.D. Qian, Z. Li, Z.X. Li, Entransy-dissipation-based thermal resistance analysis of heat exchanger networks, Chin. Sci. Bull. 56 (2011) 3289-3295

[16] X.T. Cheng, X.G. Liang, Z.Y. Guo, Entransy decrease principle of heat transfer in an isolated system, Chin. Sci. Bull. 56 (2011) 847e54

[17] X.T. Cheng, X.G. Liang, X.H. Xu, Microscopic expression of entransy, Acta Physica Sinica 60 (2011) 060512

[18] Z.H. Xie, L.G. Chen, F.R. Sun, Constructal optimization on T-shaped cavity based on entransy dissipation minimization, Chin. Sci. Bull. 54 (2009) 4418-4427

[19] Q.H. Xiao, L.G. Chen, F.R. Sun, Constructal entransy dissipation rate minimization for "disc-to-point" heat conduction, Chin. Sci. Bull. 56 (2011) 102-112

[20] J. Wu, X.G. Liang, Application of entransy dissipation extreme principle in radiative heat transfer optimization, Sci. China Ser. E Technol Sci. 51 (2008) 1306-1314

[21] S.J. Xia, L.G. Chen, F.R. Sun, Optimization for entransy dissipation minimization in heat exchanger, Chin. Sci. Bull. 54 (2009) 3572-3578

[22] X.F. Li, J.F. Guo, M.T. Xu, L. Cheng, Entransy dissipation minimization for optimization of heat exchanger design, Chin. Sci. Bull. 56 (2011) 2174-2178
[23] X.D. Qian, Z.X. Li, Analysis of entransy dissipation in heat exchangers, Int. J. Thermal Sci. 50 (2011) 608-614

[24] L. Chen, S. Wei, F. Sun, Constructal entransy dissipation rate minimization of a disc, Int. J. Heat Mass Transfer 54 (2011) 210-216

[25] L. Chen, S. Wei, F. Sun, Constructal entransy dissipation rate minimization of round tube heat exchanger crosssection, Int. J. Them Sci. 50 (2011) 1285-1292

[26] S.H. Wei, L.G. Chen, F.R. Sun, Constructal optimization of discrete and continuous variable cross-section conducting path based on entransy dissipation rate minimization, Sci. China - Technol. Sci. 53 (2010) 1666-1677

[27] S.H. Wei, L.G. Chen, F.R. Sun, Constructal entransy dissipation minimisation for 'volume-point' heat conduction without the premise of optimised last order construct, Int. J. Exergy 7 (2010) 627-639

[28] S.J. Xia, L.G. Chen, F.R. Sun, Optimal paths for minimizing entransy dissipation during heat transfer processes with generalized radiative heat transfer law, Appl. Math. Model 34 (2010) 2242-2255

[29] Q.H. Xiao, L.G. Chen, F.R. Sun, Constructal entransy dissipation rate minimization for a heat generating volume cooled by forced convection, Chin. Sci. Bull. 56 (2011) 2966-2973

[30] Q.H. Xiao, L.G. Chen, F.R. Sun, Constructal entransy dissipation rate minimization for heat conduction based on a tapered element, Chin. Sci. Bull. 56 (2011) 24002410

[31] Q.H. Xiao, L.G. Chen, F.R. Sun, Constructal entransy dissipation rate minimization for umbrella-shaped assembly of cylindrical fins, Sci. China. - Technol. Sci. 54 (2011) 211-219

[32] Z.H. Xie, L.G. Chen, F.R. Sun, Constructal optimization for geometry of cavity by taking entransy dissipation minimization as objective, Sci. China Ser. E - Technol. Sci. 52 (2009) 3504-3513

[33] Z.H. Xie, L.G. Chen, F.R. Sun, Comparative study on constructal optimizations of Tshaped fin based on entransy dissipation rate minimization and maximum thermal resistance minimization, Sci. China - Technol. Sci. 54 (2011) 1249-1258

[34] T. Özyer, M. Zhang, R. Alhajj, Integrating multiobjective genetic algorithm based clustering and data partitioning for skyline computation, Appl. Intell. 35 (2011) 110-122

[35] O. Beatrice, J.R. Brian, H. Franklin, Multi-Objective Genetic Algorithms for Vehicle Routing Problem with Time Windows, Appl. Intell. 24 (2006) 17-30

[36] I. Blecic, A. Cecchini, G. Trunfio, A decision support tool coupling a causal model and a multi-objective genetic algorithm, Appl. Intell. 26 (2007) 125-137

[37] D.A.V. Veldhuizen, G.B. Lamont, Multi objective evolutionary algorithms analyzing the state-of-the-art, Evol. Comput. 8 (2000) 125-147

[38] A. Konak, D.W. Coit, A.E. Smith, Multi-objective optimization using genetic algorithms: A tutorial, Reliab. Eng. Amp. Syst. Safe. 91 (2006) 992-1007 
[39] M.H. Ahmadi, M.A. Ahmadi, S.A. Sadatsakkak, Thermodynamic analysis and performance optimization of irreversible Carnot refrigerator by using multiobjective evolutionary algorithms (MOEAs), Renew. Sust. Energy Rev. 51 (2015) 1055-1070

[40] M.H. Ahmadi, M.A. Ahmadi, Thermodynamic analysis and optimisation of an irreversible radiative-type heat engine by using non-dominated sorting genetic algorithm, Int. J. Ambient Energy (2014) 1-6

[41] M.H. Ahmadi, M.A. Ahmadi, A. Shafaei, M. Ashouri, S. Toghyani, Thermodynamic analysis and optimization of the Atkinson engine by using NSGA-II, Int. J. LowCarbon Technol. (2015) ctv001

[42] N.M. Mahdi, S. Farahat, F. Sarhaddi, Finite time exergy analysis and multi-objective ecological optimization of a regenerative Brayton cycle considering the impact of flow rate variations, Energy Convers. Manage. 103 (2015) 790800

[43] T. Mojtaba, N. Babayan, F. Razi Astaraei, A. Moghadam, Multi objective optimization of horizontal axis tidal current turbines, using Meta heuristics algorithms, Energy Convers. Manage. 103 (2015) 487-498

[44] Arora, Rajesh, S.C. Kaushik, R. Kumar, R. Arora, Multi-objective thermo-economic optimization of solar parabolic dish Stirling heat engine with regenerative losses using NSGA-II and decision making, Int. J. Electr. Power Energy Syst. 74 (2016): 25-35

[45] M.H. Ahmadi, H. Hosseinzade, H. Sayyaadi, A.H. Mohammadi, F. Kimiaghalam, Application of the multiobjective optimization method for designing a powered Stirling heat engine: design with maximized power, thermal efficiency and minimized pressure loss, Renew. Energy (2013) 313-322

[46] M.H. Ahmadi, H. Sayyaadi, A.H. Mohammadi, M.A. Barranco-Jimenez, Thermo-economic multi-objective optimization of solar dish-Stirling engine by implementing evolutionary algorithm, Energy Convers. Manage. 73 (2013) 370-380

[47] M.H. Ahmadi, H. Sayyaadi, S. Dehghani, H. Hosseinzade, Designing a solar powered Stirling heat engine based on multiple criterion: Maximized thermal efficiency and power, Energy Convers. Manage. 75 (2013) 282-291

[48] M.H. Ahmadi, S. Dehghani, A.H. Mohammadi, M. Feidt, M.A. Barranco-Jimenez, Optimal design of a solar driven heat engine based on thermal and thermo-economic criterion, Energy Convers. Manage. 75 (2013) 635-642

[49] M.H. Ahmadi, M.A. Ahmadi, R. Bayat, M. Ashouri, M. Feidt, Thermo-economic optimization of Stirling heat pump by using non-dominated sorting genetic algorithm, Energy Convers. Manage. 91 (2015) 315-22

[50] A. Lazzaretto, A. Toffolo, Energy, economy and environment as objectives in multi-criterion optimization of thermal systems design, Energy, 29 (2004) 1139-1157

[51] S. Toghyani, A. Kasaeian, M.H. Ahmadi, Multi-objective optimization of Stirling engine using non-ideal adiabatic method, Energy Convers. Manage. 80 (2014) 54-62

[52] A. Toffolo, A. Lazzaretto, Evolutionary algorithms for multi-objective energetic and economic optimization in thermal system design, Energy 27 (2002) 549-567
[53] M.H. Ahmadi, A.H. Mohammadi, S. Dehghani, Evaluation of the maximized power of a regenerative endoreversible Stirling cycle using the thermodynamic analysis, Energy Convers. Manage. 76 (2013) 561-570

[54] M.H. Ahmadi, M.A. Ahmadi, H.M. Amir, M. Feidt, S.M. Pourkiaei, Multi-objective optimization of an irreversible Stirling cryogenic refrigerator cycle, Energy Convers. Manage. 82 (2014) 351-360

[55] M.H. Ahmadi, M.A. Ahmadi, A.H. Mohammadi, M. Mehrpooya, M. Feidt, Thermodynamic optimization of Stirling heat pump based on multiple criterion, Energy Convers. Manage. 80 (2014) 319-328

[56] M.H. Ahmadi, A.H. Mohammadi, S. Dehghani, M.A. Barranco-Jimenez, Multi-objective thermodynamicbased optimization of output power of Solar DishStirling engine by implementing an evolutionary algorithm, Energy Convers. Manage. 75 (2013) 438-445

[57] M.H. Ahmadi, A.H. Mohammadi, S.M. Pourkiaei, 2014, Optimisation of the thermodynamic performance of the Stirling engine, Int. J. Ambient Energy, DOI: 10.1080/01430750.2014.907211

[58] H. Sayyaadi, M.H. Ahmadi, S. Dehghani, Optimal Design of a Solar-Driven Heat Engine Based on Thermal and Ecological criterion, J. Energy Eng., (2014), 10.1061/(ASCE)EY.1943-7897.000019104014012.

[59] H. Sahraie, M.R. Mirani, M.H. Ahmadi, M. Ashouri, Thermo-economic and thermodynamic analysis and optimization of a two-stage irreversible heat pump, Energy Convers. Manage. 99 (2015) 81-91

[60] M.H. Ahmadi, M.A. Ahmadi, M. Mehrpooya, H. Hosseinzade, M. Feidt, Thermodynamic and thermoeconomic analysis and optimization of performance of irreversible four-temperature-level absorption refrigeration, Energy Convers. Manage. 88 (2014) 1051-1059

[61] M.H. Ahmadi, M.A. Ahmadi, Thermodynamic analysis and optimization of an irreversible Ericsson cryogenic refrigerator cycle, Energy Convers. Manage. 89 (2015) 14755

[62] M.H. Ahmadi, M.A. Ahmadi, M. Mehrpooya, M. Sameti, Thermo-ecological analysis and optimization performance of an irreversible three-heat-source absorption heat pump, Energy Convers. Manage. 90 (2015) 175-183

[63] M.H. Ahmadi, M.A. Ahmadi, M. Feidt, Performance optimization of a solar-driven multi-step irreversible Brayton cycle based on a multi-objective genetic algorithm, Oil Gas Science and Technology - Rev. IFP Energies nouvelles 2014. http://dx.doi.org/10.2516/ ogst/2014028

[64] M.H. Ahmadi, M.A. Ahmadi, M. Feidt, Thermodynamic analysis and evolutionary algorithm based on multiobjective optimization of performance for irreversible four-temperature-level refrigeration. Mech. Ind. 16 (2015)

[65] S.A. Sadatsakkak, M.H. Ahmadi, M.A. Ahmadi, Thermodynamic and thermo-economic analysis and optimization of an irreversible regenerative closed Brayton cycle, Energy Convers. Manage. 94 (2015) 124-129

[66] S.A. Sadatsakkak, et al., Optimization density power and thermal efficiency of an endoreversible Brayton cycle by using non-dominated sorting genetic algorithm, Energy Convers. Manage. 93 (2015) 31-39 
[67] S.A. Sadatsakkak, M.H. Ahmadi, M.A. Ahmadi, Optimization performance and thermodynamic analysis of an irreversible nano scale Brayton cycle operating with Maxwell-Boltzmann gas, Energy Convers. Manage. 101 (2015) 592-605

[68] L. Chen, Z. Xiaoqin, F. Sun, C. Wu, Exergy-based ecological optimization for a generalized irreversible Carnot heat-pump, Appl. Energy 84 (2007) 78-88

[69] Z. Yan, L. Chen, Optimization of irreversible rate of exergy output for an endoreversible Carnot refrigerator, J. Phys. D Appl. Phys. 29 (1996) 3017-3021

[70] J. Chen, The maximum power output and maximum efficiency of an irreversible Carnot heat engine, J. Phys. D Appl. Phys. 27 (1994) 1144-1149
[71] Y. Ust, B. Sahin, A. Kodal, Performance optimisation of irreversible cogeneration system based on a new exergetic performance criterion: exergy density, J. Energy. Inst. 82 (2009) 48-52

[72] E. Acıkkalp, H. Yamık, Limits and optimization of power input or output of actual thermal cycles, Entropy 15 (2013) 3219-3248

[73] E. Acıkkalp, Models for optimum thermo-ecological criterion of actual thermal cycles, Therm. Sci. 17 (2013) 915-930

[74] E. Açıkkalp, Entransy analysis of irreversible Carnot-like heat engine and refrigeration cycles and the relationships among various thermodynamic parameters, Energy Convers. Manage. 80 (2014) 535-542 